\title{
TRANSIVITY ON ELON MUSK'S \\ ONLINE BIOGRAPHY:A SOCIAL ACTORS DISCOURSE ANALYSIS
}

\author{
Anggihat Prasetyoaji \\ Universitas Sebelas Maret Surakarta (UNS), Surakarta, Indonesia \\ anggihatp@gmail.com
}

\begin{abstract}
This research's content is the analysis of biography texts about Elon Musk taken from four websites by combining SFL's transitivity and Leeuwen's social actor representation approach. The aims of this research are (1) to find the portrayal patterns of the social actor using social actor approach, (2) to find the linguistic evidences of the patterns using transitivity, (3) to explain the portrayal of the social actor based on the patterns found, and (4) to compare the results with the context and genre of biography. This research is categorized as a descriptive-qualitative research by using transitivity and Leeuwen's social actor approach. Spradely's method of domain, taxonomy, componential, and cultural context analysis is used to collect and analyze the data. The data sources for this research are four biography texts about Elon Musk taken from Britannica, BBC, Business Insider, and Investopedia. The research produced several results as follows: (1) various social actor representation patterns are used by the writer to convey their intention and stance in relation with the social actor, (2) the processes contained in the texts are identified by using transitivity, thus providing linguistic evidences, (3) representation patterns that are the most consistently occurring are: activation, passivation (subjection and beneficialization), determination, nomination, functionalisation, and instrumentalisation. These patterns can be deduced as the obligatory patterns in biography texts, and (4) the texts analyzed are relevant with the qualities of a biography text.
\end{abstract}

Keywords: Elon Musk; Biography; Leeuwen; Social Actor Representation; Transitivity.

\section{INTRODUCTION}

Critical Discourse Analysis (CDA), as explained by Dijk (2001), is a method to study and find how social actions and its correlation with power, dominance, and inequality are presented in a discourse with social and political context, whether they are presented as they are, or modified to suit the qualities wanted by the producer of a discourse. The main purpose of CDA is to explain an elaborate the possibly hidden relation between language, power, and ideology through the exploration of the language and contextual component (Kristina, Ardi, Pratama, \& Purnomo, 2017).

As CDA evolved, various approaches with different methods are found. These methods are Dialectical Relational Approach by Norman Fairclough, SocioCognitive Approach by Teun A. van Dijk, Social Actors Approach by Theo van Leeuwen, Discourse-Historical Approach by Ruth Wodak, and Feminist Stylistics 
Approach by Sara Mills. All of the approaches have their own advantages, and with their own focus towards varying aspects of discourse (Kristina, Ardi, Pratama, \& Purnomo, 2017).

The Social Actors Approach, first presented by Theo van Leeuwen focuses on how social actions are presented by the discourse writer (1995), and the actors involved inside the action itself (2003). These social actors are analysed by how the discourse writer tried to portray them, whether they are included or excluded in the discourse. Van Leeuwen believes that discourse maker tried to pour their ideology into the discourses they made. Therefore, the basic inclusion and exclusion pattern will always appear in a discourse, as it is the way the maker manipulate their creation. They include the social actors that they deem necessary and fitting for their purpose, and exclude any actors that would hinder and stagger their intention behind making the discourses.

From the two categories of inclusion and exclusion, van Leeuwen elaborated the classifications into a number of specific categories, which are: inclusion and exclusion (further divided into suppression and backgrounding), activation and passivation (specified into subjected and beneficialized), generalisation and specification, assimilation (further categorised into aggregation and collectivisation) and individualisation, association and dissociation, determination and indetermination, nomination and categorisation (divided into functionalization and identification), and

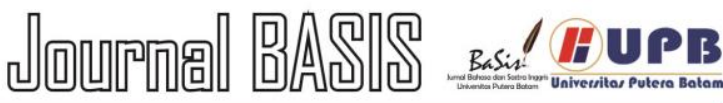

personalisation and impersonalisation. Impersonalisation itself was specified into two categories, which are abstraction and objectivation (the latter being further separated into spatialisation, utterance autonomisation, instrumentalisation and somatisation). Lastly, there is overdetermination (Leeuwen, 2003; Rashidi \& Rasti, 2012). All of these categories may appear in a discourse, concerning any social actors that are included or excluded. However, all of them are not necessarily appear altogether, depending on the discourse and the actor's construction by the maker.

In Kheirabadi \& Moghaddam (2012), KhosraviNik (2010), and Rashidi \& Rasti (2012), Social Actors Approach were applied successfully. All three researches achieved their goal in identifying the social actors involved in the newspapers they analyzed. Analyzing the language within a discourse, in this case newspapers, also falls into the study of Critical Discourse Analysis, as stated by Mubarak (2014). All of them also found the social actors' portrayal pattern, and how many times the actors are portrayed in what way. However, they are yet to relate their researches into the genre they chose, in this case news genre. Moreover, they only presented the findings without any further linguistic evidence, which leave their research lacking.

In order to provide the linguistic evidence and to complete the analysis, Social Actors Approach can be combined with other linguistic aspects. To achieve better results, Systemic Functional Linguistics (SFL) can be applied. SFL is an approach to a language developed by 
M. A. K. Halliday (Halliday \& Matthiessen, 2014; Almurashi, 2016), to analyse a text in four simultaneous aspects. They are context, semantics, lexico-grammar, and phonology. Halliday said simultaneously, because all of these four are happening together, related with each other, in a system of a language (Matthiessen \& Halliday, 1997).

The semantics aspect in SFL has three metafunction. These metafunction exist because it is believed that human language has three generalised meanings, and they refer to the different modes interpreted by grammar. They are; ideational meanings (clause as representation), interpersonal meanings (clause as exchange), and textual meanings (clause as message) (Almurashi, 2016; Halliday \& Matthiessen, 2014; Matthiessen \& Halliday, 1997).

The one metafunction that highly compatible with Social Actors Approach is the ideational meanings (clause as representation), through the use of transitivity. Said by Halliday (Halliday \& Matthiessen, 2014), transitivity is a grammatical system that identifies various actions and categorizes them into a number of process set. The categories were based on the actions done by the actors (Leeuwen, 1995). The process sets include material, mental, verbal, behavioral, relational, and existential processes.

The addition of transitivity into Social Actors Approach would help in simplifying the analitical process of a discourse, especially in the Social Actors Approach, in way that these processes are specific enough to further strengthen the actors' portrayal in a discourse. Furthermore, transitivity analysis can be used to identify and analyse persuasive style writing that could possibly appear in a discourse (Darani, 2014)

So far, only Machin \& Mayr (2013) successfully implemented the combination of Social Actors Approach and transitivity analysis. They also uniquely use CDA to analyse TV shows, something that is rarely done. They analysed the social actors involved in the show with Social Actors Approach, and resulted in factual portrayals of the actors. Then, they used transitivity to further support their arguments. They analysed the language used by those actors, whether spoken or written. Of course, because they take TV shows as their analysis, they also have to put some multimodality aspects, caused by the images contained. However, they are yet to put their research into the context and genre.

Biography writing lies between the narrative and descriptive genre, as it has the qualities of both genres. It narrates and describes a figure's life simultaneously to present a story in which the figure is the main character. As for the classifications of a biography, the standard basis for it has not been developed yet. This is caused by the thin, blur line that divide many kinds of biography writing. One type of writing might also contain the qualities of other types. By this reason, a set of rules or criteria is needed to give biography a distinguishing attribute. This research proposes the use of transitivity and social 
actor representation, which are introduced above, to find the qualities that are commonly contained within biographies. The use of social actor representation would emphasize the methods used by the writers to expose a figure in biography, and find the similarities in terms of the representation. Meanwhile, transitivity would provide the research with the linguistic evidences that social actor representation lacks.

\section{LITERATURE REVIEW}

Systemic Functional Linguistics (or SFL for short) is a variation of functional linguistics introduced by Michael Alexander Kirkwood Halliday in 1960 (Wiratno, 2018). SFL as an applicable linguistics explores a text by dividing it into four ways: Context, Semantics, Lexico-grammar, and phonology (Halliday, 2014). Context then further separated into context of culture (genre) and context of situation (register). Register has three variables, they are Field (the topic that is being discussed), Tenor (the relationship and interaction of those who are included in the text), and Mode (the form of a language, can be written or spoken, that is taken and realized by the interaction).

Stated by Halliday himself (2014) and supported by Wiratno (2018), SFL is meant to potentially help solve problems involving language around the world. It can be considered as a success seeing the increasing number of interests in SFL. A number of universities in countries around the globe have been studying and applying SFL in their curriculum. Starting from London, England, which can be said as the birthplace of SFL, the study spreads to other countries in the continent such as Austria, France, Germany, Spain,

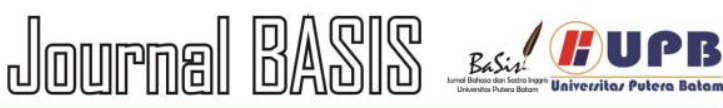

and Russia. Then, it continues to spread internationally, reaching North \& South America, Australia, and Asia. The success can not only be seen from the spread, but also from the various field it is applied on. So far, SFL has been applied in Discourse Analysis, Translation, and Language Acquisition, among others (Wiratno, 2018).

Halliday's SFL (2014) proposed three separate categories in general to accommodate the meanings that may occur in the language. They are: interpersonal metafunction (clause as exchange), ideational metafunction (clause as representation), and textual metafunction (clause as message). Interpersonal metafunction covers the interaction and transaction of communication between people. Ideational metafunction translates into experiential and logical meanings, which mean the expressed reality of the processes, participants, and circumstances of an event(s), and the logical connection of the reality. Then, textual metafunction envelops both ideational and interpersonal metafunctions by the use of language.

Transitivity is a system utilized by language users to represent their experiences. It is a method driven from experiential meanings of ideational metafunction in which clauses are associated with various processes in language framework (Wiratno, 2018), to express the reality of an event(s) processes, participants, and circumstances, as explained above.

Transitivity contains three aspects that are potentially responsible in translating the meanings. The aspects are the processes, participants, and circumstances. These three can be further separated into detailed specifications, 
depending on the representation of the clause itself. The processes are presented in the table below, along with the examples.

Table 2.1. Examples of Transitivity Processes

\begin{tabular}{|c|c|c|}
\hline \multicolumn{2}{|l|}{ Process } & $\begin{array}{l}\text { Example [Participants are } \\
\text { underlined; Processes are in } \\
\text { bold; Circumstances are in } \\
\text { italics] }\end{array}$ \\
\hline \multicolumn{2}{|l|}{ Material } & $\begin{array}{l}\text { Musk moved to Canada } \\
\text { with his mother Maye, his } \\
\text { sister Tosca, and his } \\
\text { brother Kimbal. }\end{array}$ \\
\hline \multicolumn{2}{|l|}{ Mental } & $\begin{array}{l}\text { Musk has expressed } \\
\text { concern that the race for } \\
\text { better AI could end up } \\
\text { sparking a third world war. }\end{array}$ \\
\hline \multicolumn{2}{|l|}{ Verbal } & $\begin{array}{l}\text { Musk described it as “a } \\
\text { trivial game ... but better } \\
\text { than Flappy Bird." }\end{array}$ \\
\hline \multicolumn{2}{|c|}{ Behavioral } & $\begin{array}{l}\ldots \text { Musk was dreaming up } \\
\text { his next move ... }\end{array}$ \\
\hline \multirow[t]{2}{*}{ Relational } & Identifying & $\begin{array}{l}\text { Musk is basically a real-life } \\
\text { Tony Stark }\end{array}$ \\
\hline & Attributive & $\begin{array}{l}\text { Musk had six sons with } \\
\text { Justine Musk }\end{array}$ \\
\hline \multicolumn{2}{|c|}{ Existential } & ... it was technology \\
\hline
\end{tabular}

Critical Discourse Analysis (CDA), as explained by Dijk (2001), is a method to study and find how social actions and its correlation with power, dominance, and inequality are presented in a discourse with social and political context, whether they are presented as they are, or modified to suit the qualities wanted by the producer of a discourse. Dijk (2001) described CDA as the bridge between microlevel and macrolevel analysis of a social order. Microlevel contains language use, discourse, verbal interaction, and communication in a social order. Meanwhile, macrolevel is comprised of Language use, discourse, verbal interaction, and communication. In order to bridge these levels, Dijk proposed these elements: membersgroups, actions-processes, context-social culture, and personal-social cognition. In short, the main purpose of CDA is to explain an elaborate the possibly hidden relation between language, power, and ideology through the exploration of the language and contextual component (Kristina, Ardi, Pratama, \& Purnomo, 2017).

Critical Discourse Analysis has 6 (six) main approaches in its purpose of unraveling the ideology of a discourse (Kristina, Ardi, Prananta, \& Purnomo, 2017). Among the approaches, Theo van Leeuwen focused the discourse analysis to the representation of social actors that are included or excluded in a discourse (van Leeuwen, 2003). In his article entitled The Representation of Social Actors in C.R. Caldas-Coulthard \& M. Coulthard (2003, p. 32-70), van Leeuwen asked two questions: what are the ways in which social actors can be represented in English discourse? Which choices does the English language give us for referring to people?

van Leeuwen (2003) stated that the first question is a grammatical question. $\mathrm{He}$ linked the question to Halliday's statement that grammar is a meaning potential rather than a set of rules. What he meant was the representation of social actors is able to be interpreted as the grammatical construct suggests. The grammar does not limit and strict the possible interpretation, just as Halliday had stated. However, van Leeuwen opposed Halliday on the account of congruency. Halliday saw congruency as whether the linguistic realizations are congruent with the grammatical system or 
not. Meanwhile, van Leeuwen viewed congruency as whether the realizations are congruent with reality or not. He also expressed his view that meanings can be influenced by culture instead of language.

Considering the wide array of elements such as transitivity and social actors' representation, this research does not directly support the findings of previous researches. Rather than that, this research covers the gap in social actor representation, transitivity, and biographical writing instead. The results of this research would be the example of how transitivity and social actor representation combined together. Furthermore, this research has found the basic patterns that are obliged to appear in a biographical writing. The results of this research will help to advance the field of Critical Discourse Analysis. Specifically, the results will open a new field in Critical Discourse Analysis of biographies.

\section{METHODS}

This research, in essence, is a discourse analysis. Discourse analysis is used as the main method of this research. It is chosen because the wide-covering nature of the subject. However, the research is discussing about an online, written text, instead of a spoken text or any other kind. Stated by Dijk (2001) that although the discourse analysis of a spoken conversation is different from an analysis of a news report text, the conceptual and theoretical frameworks are closely related.

Critical Discourse Analysis with its various approaches has been applied to analyze media. That is another reason on why this research used CDA with Social

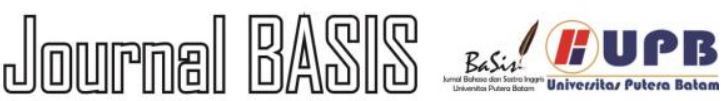

Actors Approach as its main method, considering the chosen discourse is an online written text. This is not uncommon, as a lot of researches had been done using Social Actors Approach to analyze newspapers, mainly of political nature (Kheirabadi \& Moghaddam, 2012; Rashidi \& Rasti, 2012).

The inclusion of SFL as a complementary method would increase the validity of this research. In the form of transitivity, SFL could provide the necessary linguistic evidence that Social Actors Approach lacked. Both transitivity and Social Actors Approach combined will present a strong, yet diverse method to analyse a discourse. Social Actors Approach as method will influence this research's data selection, data gathering, analysis, and interpretation. Meanwhile, SFL as method will influence this research's data analysis and interpretation.

This research is a qualitative research, because it deals with discourse analysis, social actors and their portrayal, and transitivity process in online biographies. Despite that, this research may contain a few quantitative elements to count and sum up the results. This is allowed because of the flexibility a qualitative research has (Santosa, 2017). This research has a naturalist paradigm due to a few reasons. First, discourse analysis has multi-heterogenic phenomenon. And then, discourse analysis is always bound to the context.

This discourse analysis research is a descriptive research, considering that Social Actors Approach and transitivity will show the relation between processes, 
social actors, and the online biographies. These relations will be described as necessary to fulfil the research objectives.

The data is gathered from four websites, namely Britannica, BBC, Business Insider, and Investopedia. These four websites are chosen due to the same figure they wrote about: Elon Musk. He is chosen as the figure because of his rising popularity in media, which would provide ample data regarding his life story. Next, the four texts of biography from four websites were read thoroughly, and then broken up into clauses in preparation to do transitivity analysis. Each clause would be examined to figure its processes, actors, and circumstances. After doing so, the results are compared with social actor representation to find the most fitting pattern of Elon Musk's representation. The patterns found then are read and analyzed to discover the overall theme and flow of the texts.

From four texts, 214 data were found. These data are found spread across various patterns of social actor representation and transitivity processes. The summary of this findings would be explained further in the next chapter.

\section{RESULTS AND DISCUSSIONS}

All four texts are dominated by material process, transitivity-wise. It is inferred that all writers have similar goal in writing biography text. The repeated use of material process can translate into the preference of presenting physical events in order to give the readers a solid image of Elon Musk.

Similar to previous found pattern, activation pattern is the most occurring pattern on all texts. It can be deduced that the writers wanted to present Elon Musk as the actor as often as possible in a biography writing. On the other hand, passivation patterns are used sparingly. This implies that the writers decided that active representation would provide stronger impression than passive patterns. On the cases where passive patterns are used, it can be deducted that presenting Elon Musk as the receiving actor would induce sympathy from the readers.

Table 4.1. Complete analysis of the patterns found in four texts

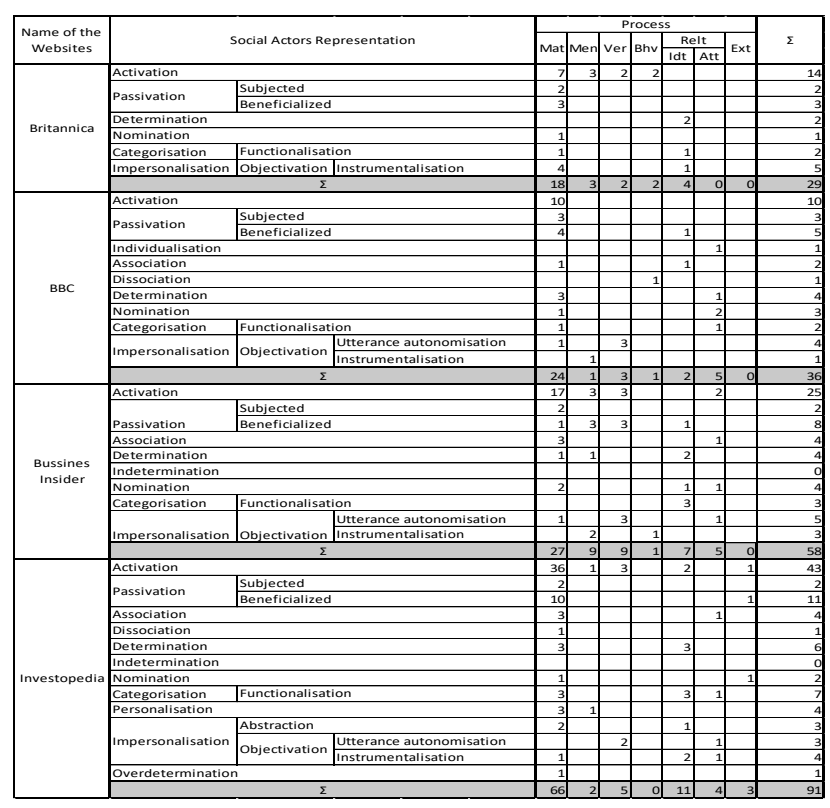

In all four texts, these patterns are consistently occurring: activation, passivation (subjected, beneficialized), determination, nomination, functionalisation, and instrumentalisation. It is deduced that in a biographical writing, these patterns are the compulsory patterns. A biography text would be bound to contain these patterns. Other patterns may appear in a biography text to 
add more variety, but are not as necessary as these patterns.

All four texts are bound to consist of these processes: material, mental, verbal, and identifying relational process. While other processes (behavioral, attributive relational, and existential process) can appear, those processes are not as necessary as the previously mentioned processes. It can be concluded that a biography would contain the compulsory transitivity processes (material, mental, verbal, and identifying relational process). The absence of the additional transitivity processes (behavioral, attributive relational, and existential process) will not hinder the biography, but the addition would certainly support and strengthen the content of the biography itself.

Previous researches using transitivity had been carried out by other researchers in another topic. The same can also be said about researches using social actor representation. So far, there are only a small number of researches that combined both transitivity and social actor representation. In this instance, a research by Machin \& Mayr (2013) successfully combined the analysis of transitivity and social actor representation. However, the research itself cannot be directly compared this research because of the difference in topic. Machin \& Mayr analyzed television shows about crime, while this research is analyzing biography. Another small yet significant difference is Machin \& Mayr also used multimodality in their research. Multimodality itself suited the object of their analysis, but the same method cannot be applied to biography.

Other researches that used social actor representation are the researches done by Rashidi \& Rasti (2012), KhosraviNik (2010) and Kheirabadi \& Moghaddam (2012). They had analyzed news items using social actor representation. The difference between their research and this research is the number of the actor being analyzed. News items tend to have more than one actor, while biography normally revolved around one actor only. At the very least, this research can get examples from previous researches on how to identify a social actor and its pattern.

One research about biography that is taken into account is the research done by Amir (2007), with his research of B.J. Habibie. Rather than researching about the biography of B.J. Habibie, he analyzed the figure of Habibie himself. That reason can make his own research classified as biography, to some extent.

The main source of comparison for this research is the research of Theo van Leeuwen (2003) about social actor representation. In his research, he stated:

"Activation occurs when social actors are represented as the active, dynamic forces in an activity, passivation when they are represented as 'undergoing' the activity, or as being 'at the receiving end of it'. This may be realised by grammatical participant roles, by transitivity structures in which activated social actors are coded as Actor in material processes, Behaver in behavioural processes, Senser in 
mental processes, Sayer in verbal processes or Assigner in relational processes," (van Leeuwen, 2003).

Looking back to this research, the statement is proven true by observing the number of activation and passivation patterns that occurred in the transitivity processes. The analyzed texts mainly consisted of material process, and contain high occurrence of activation and passivation patterns. The minimal usage of existential process and the occurring patterns within it can also be linked to this trend.

However, the high number of processes that may occur in a biography text did not always translate into high number of social pattern occurrence. This can be caused by the high number of minor and supporting clauses that were referring to the main clauses. For that reason, the patterns were found mostly on the main clauses, although it did not remove the possibility of each clause to contain its own social actor pattern. This also present another weak point of this combined method. A pattern that occurred in a main clause might be replaced with other pattern once the following clauses have been analyzed and taken into account.

Considering the findings that have been found, the compulsory patterns that are bound to appear in a biography text, and the results of previous researches, this research does not directly support the findings of previous researches. Rather than that, this research compliments the gap in social actor representation, transitivity, and biographical writing instead. The results of this research would be the example of how transitivity and social actor representation combined together. Furthermore, this research has found the basic patterns that are obliged to appear in a biographical writing. The results of this research will help to advance the field of Critical Discourse Analysis. Specifically, the results will open a new field in Critical Discourse Analysis of biographies.

\section{CONCLUSION}

Based on the findings, biography texts are proven to have certain traits. One of the traits are the consistent use of social actor representation patterns. The patterns that are commonly found in four texts are: activation, passivation (subjection and beneficialization), individualization, association, dissociation, determination, nomination, functionalisation, personalisation, abstraction, utterance autonomisation, instrumentalisation, and overdetermination. Once the four texts have been compared with one another, it is concluded that several patterns consistently occurred in every text at least once. The patterns are: activation, passivation (subjection and beneficialization), determination, nomination, functionalisation, and instrumentalisation. These patterns can be considered as the compulsory patterns that are bound to appear on a biography writing. It is crucial for a biography to contain these patterns at least once. Other patterns are additional for a biography writing, where their presence would increase the variety of the text, yet their 
absence would have minimal impact for the text itself.

With the finding of the patterns, it can be concluded that the writers preferred to portray the figure of Elon Musk as the active force within the text. He can be presented as the actor of events, speaker of speeches, and thinker of thoughts. The writers also employed his qualities using nomination and functionalisation, which represent Elon Musk's attributes and identifiers.

\section{REFERENCES}

Almurashi, W. A. (2016). An Introduction to Halliday's Systemic Functional Linguistics. Journal for the Study of English Linguistics. $\quad 4(1), \quad 70-80$. http://www.macrothink.org/journa 1/index.php/jsel/article/view/9423

Amir, S. (2007). Symbolic Power in a Technocratic Regime: The Reign of B.J. Habibie in New Order Indonesia. Journal of Social Issues in Southeast Asia, 22(1), 83-106. https://www.jstor.org/stable/4130 8087

Darani, L. H. (2014). Persuasive style and its realization through transitivity analysis: A SFL perspective. Procedia - Social and Behavioral Sciences, 10(2), 179 - 186. DOI:10.1016/j.sbspro.2014.12.06 6

Dijk, T. A. (2001). Critical Discourse Analysis. In D. Schiffrin, D. Tannen, \& H. E. Hamilton (Eds.),
The Handbook of Discourse Analysis (pp. 352-371). Massachusetts: Blackwell Publishers.

Halliday, M. (2014). Halliday's Introduction to Functional Grammar (4th ed.). London: Routledge.

Kheirabadi, R., \& Moghaddam, S. B. (2012). The Linguistic Representation of Iranian and Western Actors of Iran's Nuclear Program in International Media: A CDA Study. Theory and Practice in Language Studies, IJSCL. 2(1), 16-33. http://www.ijscl.net/ article/view/932

KhosraviNik, M. (2010). The representation of refugees, asylum seekers: A critical discourse analysis. Journal of Language and Politics, 5(1), 1-28. https://doi.org/10.1075/jlp.9.1.01k ho

Kristina, D., Ardi, H., Prananta, A. Y., \& Purnomo, S. L. (2017). Analisis Wacana Kritis. Surakarta: UNSPress.

Leeuwen, T. (1995). Representing Social Action. Sage Journals, 6(1), 81106. https://www.jstor.org/stable/4288 7962

Leeuwen, T. (2003). The Representation of Social Actors. In C. R. CaldasCoulthard, \& M. Coulthard (Eds.), Texts and Practices: Readings in 
Critical Discourse Analysis (pp. 32-70). London: Routledge.

Machin, D., \& Mayr, A. (2013). Personalising Crime and Crimefighting in Factual Television: An Analysis of Social Actors and Transitivity in Language and Images. Critical Discourse Studies. Critical Discourse Studies. 15(3), 356-372. https://doi.org/10.1080/17405904. 2013.813771

Matthiessen, C., \& Halliday, M. A. (1997). Systemic Functional Grammar: A First Step into the Theory.

Rashidi, N., \& Rasti, A. (2012). Doing (in) Justice to Iran's Nuke Activities? A critical Discourse Analysis of News Reports of Four Western Quality Newspapers. American Journal of Linguistics. 1(1), 1-9. DOI: 10.5923/j.linguistics.20120101.01

Santosa, R. (2017). Metode Penelitian Kualitatif Kebahasaan. Surakarta: UNS Press.

Wiratno, T. (2018). Pengantar Ringkas Linguistik Sistemik Fungsional. Yogyakarta: Pustaka Pelajar. 
